\title{
Primary Aortic Sarcoma: Rare and with Heterogeneous Presentations
}

\author{
Angela Pucci, MD, $\mathrm{PhD}^{1}$ Andrea De Martino, $\mathrm{MD}^{2}$ \\ ${ }^{1}$ Division of Pathology, University Hospital, Pisa, Italy \\ ${ }^{2}$ Division of Cardiac Surgery, University Hospital, Pisa, Italy
}

Aorta (Stamford) 2021;9:199-200.

\author{
Uberto Bortolotti, MD2
}

Address for correspondence Uberto Bortolotti, MD, Largo Traiano 23, 35036 Montegrotto Terme, Italy (e-mail: uberto48@gmail.com).
In the December 2019 issue of AORTA, Tessitore et al ${ }^{1}$ presented the case of intimal sarcoma of the descending aorta in a 48-year-old man, diagnosed by a combination of computed tomography, magnetic resonance imaging, and 18F-fluorodeoxyglucose positron emission tomography (PET). The definitive diagnosis was achieved with a left thoracoscopic surgical biopsy demonstrating a primitive sarcoma of the aortic intima.

Intimal sarcomas are extremely rare neoplasms, involving mostly the pulmonary artery and the aorta, with a dismal prognosis. ${ }^{2}$ Since the clinical presentation is often nonspecific, preoperative diagnosis is difficult and most neoplasms are recognized only at histological analysis of surgical specimens. We reported a case similar to that described by Tessitore et al ${ }^{1}$ in an elderly male patient, presenting with a pseudoaneurysm of the descending aorta, at the thoracoabdominal transition, close to the origin of the celiac trunk; the initial diagnosis of aortitis was justified by increased inflammatory blood markers, positivity of blood cultures, and intense tracer uptake in the aortic wall at $18 \mathrm{~F}$-fluorodeoxyglucose PET. ${ }^{3}$ Pseudoaneurysm resection was performed through a left thoracotomy, combined with laparotomy with retroperitoneal approach, with the aid of left heart bypass, under moderate hypothermia, instituted by cannulating the left femoral artery, and the left inferior pulmonary vein. Suspecting the inflammatory nature of the aortic lesion, the pseudoaneurysm was transected and the aorta replaced with the interposition of a cryopreserved aortic homograft. Based on histology and immunohistochemistry, an intimal aortic sarcoma was diagnosed (-Fig. 1).
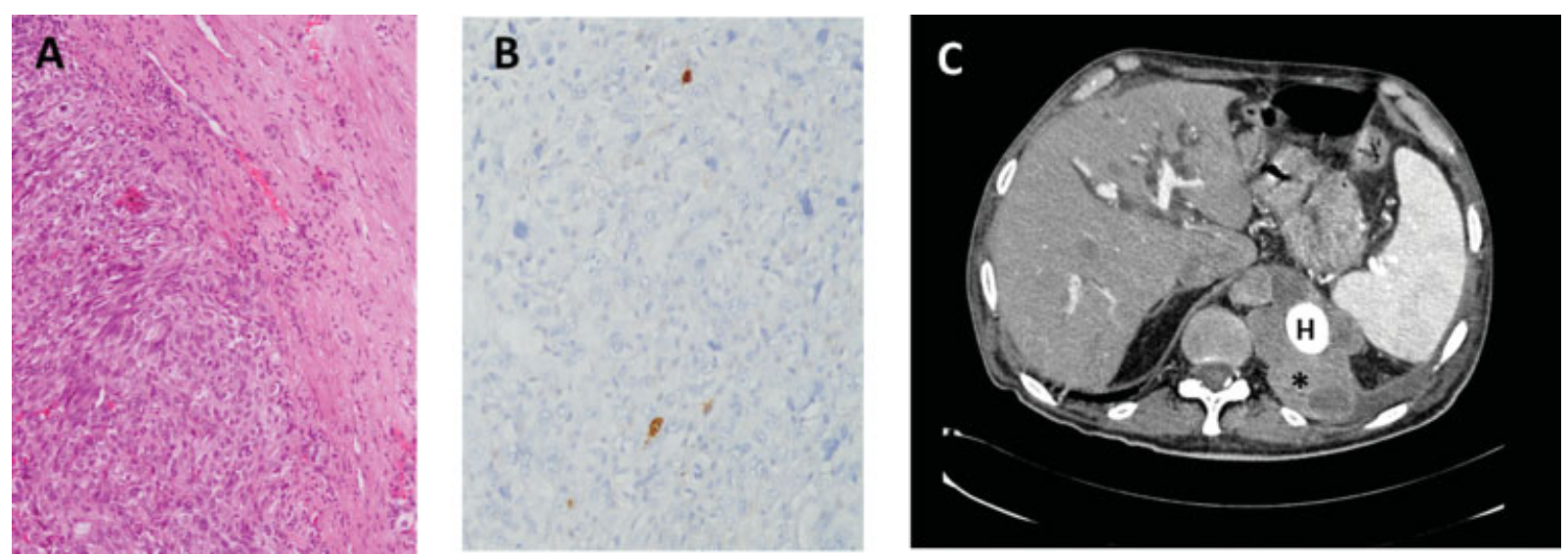

Fig. 1 (A) The aortic wall is infiltrated by high-grade and pleomorphic intimal sarcoma (hematoxylin and eosin, $\times 10$ ), which shows, by immunohistochemistry, (B) nuclear expression of the amplified MDM2 gene (immunoperoxidase technique with hematoxylin counterstaining, $\times 20)$. (C) Computed tomography, 1 year after surgery, shows neoplasm recurrence (asterisk) around the homograft $(\mathrm{H})$ involving the esophagus and diaphragm.

received

July 1,2020

accepted after revision

February 25, 2021
DOI https://doi.org/

10.1055/s-0041-1729914.

ISSN 2325-4637.
(C) 2021. The Author(s).

This is an open access article published by Thieme under the terms of the Creative Commons Attribution License, permitting unrestricted use, distribution, and reproduction so long as the original work is properly cited. (https://creativecommons.org/licenses/by/4.0/)

Thieme Medical Publishers, Inc., 333 Seventh Avenue, 18th Floor, New York, NY 10001, USA 
This case confirms the rarity and malignancy of neo-

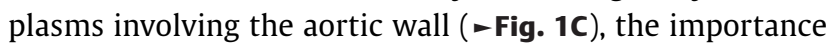
of routine histologic examination of the aortic wall specimens excised at surgery to allow the definitive diagnosis in patients with aortic pathologies ${ }^{4}$ and the heterogeneity of clinical presentation that can mimic less serious aortic diseases. ${ }^{3}$ For such reasons when reporting on uncommon diseases, such as those involving the aorta, previous important contributions on the same issue should not be overlooked.

\section{Funding}

None.

\section{Conflict of Interest}

The authors declare no conflict of interest related to this article.

\section{Acknowledgment}

None.

\section{References}

1 Tessitore A, Mariolo AV, Galetta D, Sedda G, Spirito R, Spaggiari L. Primary sarcoma of the descending aorta. Aorta (Stamford) 2019; 7(06):169-171

2 Sebenik M, Ricci A Jr., DiPasquale B, et al. Undifferentiated intimal sarcoma of large systemic blood vessels: report of 14 cases with immunohistochemical profile and review of the literature. Am J Surg Pathol 2005;29(09):1184-1193

3 Pucci A, De Martino A, Levantino M, Berchiolli R, Basolo F, Bortolotti U. Intimal sarcoma of the descending aorta mimicking aortitis. Aorta (Stamford) 2016;4(04):142-145

4 De Martino A, Ballestracci P, Faggioni L, et al. Incidence of aortitis in surgical specimens of the ascending aorta. Clinical implications at follow-up. Semin Thorac Cardiovasc Surg 2019;31(04):751-760 